Summary This study evaluated subjects' impressions of performance of high-intensity discharge (HID) headlamps after in-traffic experience, with an emphasis on colour appearance of red stop signs. In the first of two tasks, subjects drove (or rode) for half an hour on a variety of roads in a car equipped with either HID or tungsten-halogen low-beam headlamps. Instructions did not mention colour appearance. The second task involved a direct comparison of HID and tungsten-halogen headlamps. In this task, subjects drove (or rode) twice along a 7-minute route in a residential area, and they were instructed to pay attention to the colour appearance of stop signs and other objects. The main finding from Task 1 is that subjects who experienced HiD headlamps did not report more (or fewer) spontaneous negative comments on colour appearance of stop signs or other objects than did subjects who experienced tungsten-halogen headlamps. Furthermore, the evaluations of the overall performances of the two types of headlamps were not different. In the direct comparison of Task 2 there was no evidence of problems with colour appearance when using HD headlamps. Moreover, subjects preferred Ho headlamps in terms of the overall performance, and in making stop signs and other objects stand out from their background. However, this preference for HID headlamps was present only for subjects who had the relatively extended exposure to the HID headlamps in Task 1 . The present results provide no evidence for problems with colour appearance of stop signs and other objects when using HID headlamps. Furthermore, the study provides evidence that observers perceive Hid headlamps as helping stop signs and other objects to stand out from their background. The results imply that given a somewhat extended exposure to HID headlamps, drivers would prefer them over current tungsten-halogen headlamps.

\title{
Evaluations of in-traffic performance of high-intensity discharge headlamps
}

\author{
M Sivak PhD, M J Flannagan PhD, E C Traube, D S Battle and T Sato \\ The University of Michigan Transportation Research Institute, 2901 Baxter Road, Ann Arbor, Michigan 48109-2150, USA \\ Received 25 April 1994, in final form 8 September 1994
}

\section{Introduction}

The development of high-intensity discharge (HID) headlamps (also called gas-discharge headlamps) has raised questions regarding the colour perception of retroreflective stop signs. The reason for this concern is that HID light sources, in comparison to tungsten-halogen light sources, emit proportionally less energy in the long-wavelength end of the visible spectrum-precisely in the most reflective wavelength region of the red component of retroreflective stop signs. (In the United States, stop signs are red with white letters and borders, and are octagonal in shape.)

As part of our research programme, we performed three previous studies related to the issue of colour perception when using HID headlamps. The first, analytical study ${ }^{(1)}$ evaluated the colorimetric properties of retroreflective traffic signs when illuminated by HID headlamps. Two aspects were investigated: $(a)$ colorimetric shift of individual sign materials when illuminated by HID as opposed to tungsten-halogen light sources, and $(b)$ colorimetric separations of the red sign material from the yellow, orange, and brown sign materials when illuminated by HID light sources. Spectral reflectances of 14 sign materials and spectral power distributions of seven IID headlamps (along with a tungsten-halogen headlamp) were used to derive the CIE tristimulus values for the sign materials. These values were then transformed into the CIELAB space-a perceptually uniform colour space. The results of the analyses indicated that the magnirude of the colorimetric shift increased with increasing correlated colour temperature of the light source. The resulting colorimetric separations of red from yellow, orange, and brown for the HID light sources also tended to increase with increasing correlated colour temperature.
The second of our previous studies was a photometry study ${ }^{(2)}$, designed to compare the magnitudes of the shifts in chromaticity of stop signs illuminated by HID and tungsten-halogen headlamps relative to the range of chromaticities of stop signs under tungsten-halogen headlamps. A stratified sample of 25 stop signs was selected in Ann Arbor, Michigan. Stratification was by sign material (enclosed, encapsulated, microprism), age (more than five years in service, less than one year in service), and compass direction faced by the legend side of the sign (north, south). The chromaticities of these signs were measured in the field under both tungsten-halogen and HID (DI) illumination. The shifts between the chromaticities of the signs when they were illuminated with the tungsten-halogen and the HID light sources were in the direction of orange, and they were moderate relative to the range of chromaticities under the tungsten-halogen source. We concluded that, although the sizes of the shifts should not be interpreted as indicating a problem with colour rendering by HID headlamps, they were not small enough to allow us to dismiss the possibility of a problem.

The third study was a laboratory investigation ${ }^{(3)}$, designed to address experimentally the consequences of colorimetric shifts of red sign materials in different colorimetric directions. Subjects were shown individual colour samples under controlled lighting conditions. Their task was to indicate, on each trial, whether the sample colour was acceptable for stop signs. Additionally, at the end of each experimental session, subjects were asked to select a single, most appropriate colour for stop signs from among 16 simultaneously presented colour samples. An implicit assumption underlying this study was that subjective preference is related to performance; stimuli that are closer to the most preferred stimulus lead to better performance in terms of measures such as percent correct identification, reaction time, etc. Although direct evidence 


\section{Sivak et al.}

confirming this assumption does not exist, there is some indirect evidence. Stimulus-response situations that are compatible with population stereotypes lead to shorter reaction times than siruations that are incompatible with population stereotypes $^{(4)}$. There were two main findings of this study. First, there was an overwhelming agreement among the subjects concerning the most appropriate red colour for stop signs out of the 16 colours presented-a saturated red. Second, observers were differentially sensitive to colorimetric shifts in different directions from this most appropriate colour. From among the investigated colorimetric shift directions, subjects were most sensitive to hue shifts towards orange (generally in the same direction as the shift that was obtained in the abovementioned photometric study of in-use stop signs $\left.{ }^{(2)}\right)$, while they were relatively insensitive to saturation shifts towards pink.

These three studies suggest that (i) HID headlamps result in colorimetric shifts of the red stop-sign materials towards orange, and (ii) observers in a laboratory setting are sensitive to such shifts, and they prefer the situation under tungsten-halogen over HID illumination. However, it is not clear how these findings would influence driver evaluation of headlamp performance. Consequently, the present study was designed to investigate the influence of actual driving context on (1) colour perception using HID and tungsten-halogen low-beam headlamps, and (2) observer preferences for HID versus tungsten-halogen headlamps.

\section{Tasks}

\subsection{Task 1}

The first of two tasks provided in-traffic experience with either HID or tungsten-halogen headlamps. No specific instructions concerning the purpose were given prior to this task. The instructions indicated that subjects would be driving or riding in a car for about half an hour. They were instructed to look around as they were driving (or riding), noticing anything that they felt might be different or worth noting.
At the end of the drive, all subjects were asked to fill out a questionnaire containing 16 questions. The questions (see Table 1) started with general inquiries concerning the performance of the headlamps. Progressively, the questions became more specific concerning colour perception in general, colour perception of traffic signs, and colour perception of stop signs and vehicle rear lights. Each page of the questionnaire contained one question, in order to avoid influencing the responses to early questions by later questions.

The route was $19.4 \mathrm{~km}$ long, and it consisted of the following segments: a four-lane rural divided roadway without limited access $(3.2 \mathrm{~km})$, two-lane residential streets $(7.1 \mathrm{~km})$, a twolane rural roadway $(2.6 \mathrm{~km})$, a four-lane rural limited-access roadway $(3.9 \mathrm{~km})$, and a five-lane suburban non-divided roadway $(2.6 \mathrm{~km})$. Subjects encountered a total of 17 stop signs on this route.

\subsection{Task 2}

This task involved a direct comparison of HID and tungsten-halogen headlamps. In this task, subjects drove (or rode) twice along a short route in a residential area. Prior to this task, the subjects were instructed to 'pay attention to how colours look with these headlamps. We would like you to pay special attention to the red colour of stop signs.'

The route in this task was $3.9 \mathrm{~km}$ long, and it consisted mostly of two-lane residential streets. Subjects encountered a total of seven stop signs on this route. It took subjects about seven minutes to traverse this route each time.

After completing the two runs of Task 2, subjects were given a brief questionnaire concerning each of the two headlamp types (see Table 2).

\section{Equipment}

Two cars were used as subject vehicles: a 1990 Cadillac Sedan de Ville, and a 1992 Cadillac Eldorado. Each of the two cars was equipped with both HID and tungsten-halogen low-beam

Table 1 Questions in Task 1 (All questions, with the exception of questions 9,10 and 15, used the following five-point response scale: $1=$ very poor, $2=$ poor, $3=$ fair, $4=$ good, $5=$ very good.)

\begin{tabular}{ll}
\hline Number & Question \\
\hline 1 & What is your impression concerning the performance of these headlamps? \\
2 & What is your impression concerning the performance of these headlamps on expressways? \\
4 & What is your impression concerning the performance of these headlamps on residential streets? \\
5 & What is your impression concerning the performance of these headlamps on straight sections of road? \\
6 & What is your impression concerning the performance of these headlamps on curved sections of road? \\
7 & How good were the headlamps in helping to detect objects in the distance? \\
8 & How good were the headlamps in making objects to stand out from their background? \\
9 & How good were the headlamps in helping you see the colours of objects? \\
10 & Did you notice anything particular about traffic signs? (Yes or No.) If yes, indicate what. \\
11 & Did you notice anything particular about stop signs? (Yes or No.) If yes, indicate what. \\
12 & Rate the visibility of stop signs at far distance. \\
13 & Rate how well stop signs stood out from the background. \\
14 & Rate the legibility of stop signs. \\
15 & Rate the quality of the red colour of stop signs. \\
16 & Did you notice anything particular about the brake and tail lights on vehicles ahead of you? (Yes or No.)
\end{tabular}


Table 2 Questions in Task 2 (All questions used the following five-point response scale: $1=$ very poor, $2=$ poor, $3=$ fair, $4=$ good, $5=$ very good.)

\begin{tabular}{ll}
\hline Number & Question \\
\hline 1 & Rate the overall performance of each lamp type. \\
2 & Rate the performance of each lamp type in making objects in general stand out from their background. \\
3 & Rate the performance of each lamp type in helping you to see the colours of objects in general. \\
4 & Rate the performance of each lamp type in making stop signs stand out from their background. \\
5 & Rate the performance of each lamp type in helping you to see the colour of stop signs.
\end{tabular}

headlamps. The spectral power distributions for the four HID lamps were examined and were found to be very similar. Figure 1 shows the spectral power distributions for one of the HID lamps, along with a typical distribution for a tungsten-halogen lamp.

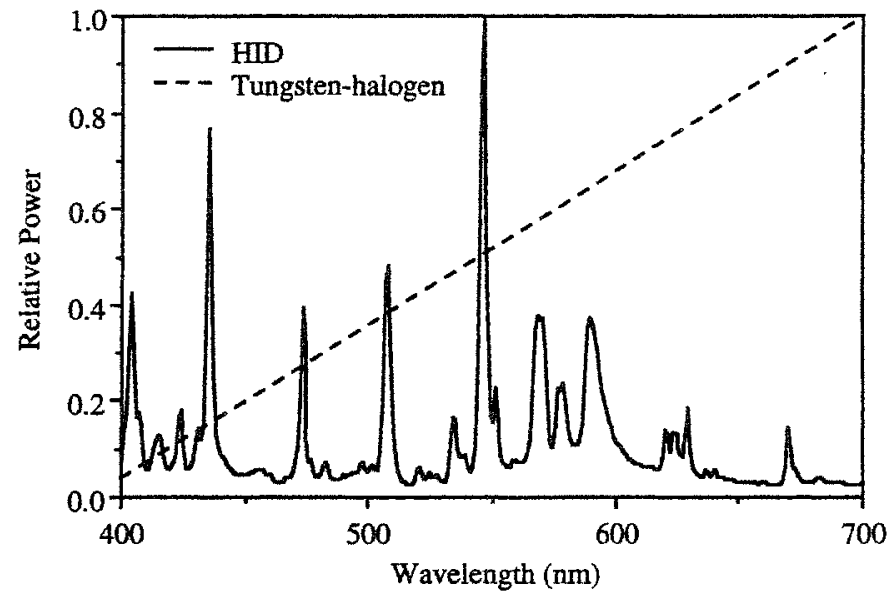

Figure 1 The relative spectral power distributions of a typical tungsten-halogen headlamp and of one of the four HID headlamps used in this study. (The power distributions of all four utD headlamps were very similar.)

Figure 2 shows the luminous intensity values at 14 test points (or regions) that evaluate the compliance with the United States regulations ${ }^{(5)}$ for all eight headlamps (four tungsten-halogen and four HID) used in this study. The locations of the test points are listed in Table 3. A visual inspection of Figure 2 indicates that the two types of headlamps had similar light output at these test points. However, the maxi-

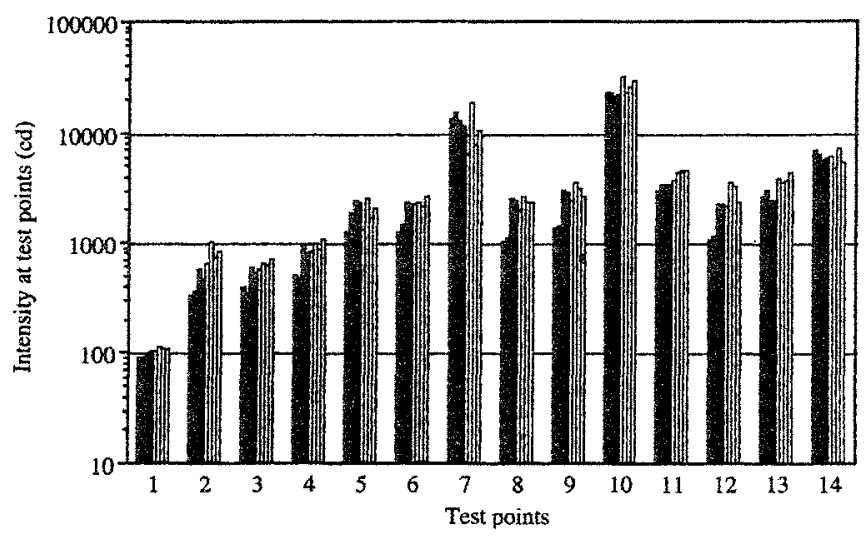

Figure 2 Luminous intensity values at 14 test points (or regions) that evaluate the compliance with the United States Federal Motor Vehicle Safety Standard 108 for all eight headlamps used in this study. The locations of these test points are listed in Table 3 . The shaded bars represent the tungsten-halogen headlamps and the open bars the HID headlamps.
Table 3 Locations of the test points in Figure $2(\mathrm{U}=$ up, $\mathrm{D}=$ down, $\mathrm{L}=$ left, $\mathrm{R}=$ right)

\begin{tabular}{llll}
\hline $\begin{array}{l}\text { Number } \\
\text { (from Figure 2) }\end{array}$ & Location & $\begin{array}{l}\text { Photometric } \\
\text { maximum }\end{array}$ & $\begin{array}{l}\text { Photometric } \\
\text { minimum }\end{array}$ \\
\hline 1 & $10^{\circ} \mathrm{U}, 5^{\circ} \mathrm{L}$ to $10^{\circ} \mathrm{R}$ & $\times$ & \\
2 & $1.5^{\circ} \mathrm{U}, 1^{\circ} \mathrm{R}$ to $10^{\circ} \mathrm{R}$ & $\times$ & \\
3 & $1^{\circ} \mathrm{U}, 1.5^{\circ} \mathrm{L}$ & $\times$ & \\
4 & $0.5^{\circ} \mathrm{U}, 1.5^{\circ} \mathrm{L}$ & $\times$ & \\
5 & $0.5^{\circ} \mathrm{U}, 1^{\circ} \mathrm{R}$ to $3^{\circ} \mathrm{R}$ & $\times$ & \\
6 & $0.5^{\circ} \mathrm{D}, 1.5^{\circ} \mathrm{L}$ & $\times$ & $\times$ \\
7 & $0.5^{\circ} \mathrm{D}, 1.5^{\circ} \mathrm{R}$ & $\times$ & $\times$ \\
8 & $1^{\circ} \mathrm{D}, 6^{\circ} \mathrm{L}$ & & $\times$ \\
9 & $1.5^{\circ} \mathrm{D}, 9^{\circ} \mathrm{L}$ & & $\times$ \\
10 & $1.5^{\circ} \mathrm{D}, 2^{\circ} \mathrm{R}$ & & $\times$ \\
11 & $1.5^{\circ} \mathrm{D}, 9^{\circ} \mathrm{R}$ & & $\times$ \\
12 & $2^{\circ} \mathrm{D}, 15^{\circ} \mathrm{L}$ & & $\times$ \\
13 & $2^{\circ} \mathrm{D}, 15^{\circ} \mathrm{R}$ & & \\
14 & $4^{\circ} \mathrm{D}, 4^{\circ} \mathrm{R}$ & $\times$ & \\
\hline
\end{tabular}

mum light output was greater for the HID lamps (ranging from 29612 to $32449 \mathrm{~cd}$ for the four lamps) than for the tungsten-halogen lamps (ranging from 21105 to $23477 \mathrm{~cd}$ for the four lamps). Furthermore, the isocandela diagrams (not shown) revealed that the HID headlamps provided more lateral-spread illumination (which is not controlled by the United States or European regulations).

\section{Subjects}

The same 36 paid subjects participated in both tasks. There were six males and six females in each of three age groups: younger (17-30 years of age, mean 23.6); middle-aged (36-46 years of age, mean 40.1$)$; and older (60-82 years of age, mean 67.7).

\section{Procedure}

Three subjects of the same sex and age group were tested at a time. Males were always tested in the Sedan de Ville (because this vehicle was somewhat roomier), and they all sat in the front seat. Females were tested in the Eldorado; because it had two front bucket seats (rather than a bench seat like the Sedan de Ville), one of the three females sat in the centre of the back seat and leaned forward so that her view would be similar to that from the front centre seat. (One of the younger females originally scheduled did not arrive for the study. Consequently, the remaining two younger females who were scheduled for that time period were run as a driver and a front-seat passenger, respectively, and a third younger female was run singly on another night in the centre rear seat.)

Groups of six subjects were scheduled simultaneously. However, to keep the two test cars separated, there was a fiveminute delay before the second group of three subjects left for 
the route. Subjects chose among themselves who would drive and who would sit in the other two positions during the study. Two groups of six subjects (all from the same age group) were tested each night. All testing was done in October 1992 between about an hour after sunset and midnight.

In Task 1 each subject travelled the entire route using only one type of headlamp. For half the subjects in each age-by-sex group the type was HID, and for the other half it was tungsten-halogen. In Task 2 all subjects used both types of headlamps. For all groups of subjects, the system that was used in Task 1 was the first one to be used in Task 2.

After completing the questionnaire of Task 1 , subjects vere given a short break. Subjects were then informed that in Task 2 they would be asked to traverse a different, shorter route twice using two different headlighting systems consecutively, and that during these two runs they should pay special attention to the colour of stop signs and other objects. After these two runs, a second questionnaire was administered. A schematic diagram of the design of both tasks is shown in Figure 3.

An experimenter was seated in the rear seat of each test vehicle. He instructed the driver concerning the route to be taken by indicating where to turn.

Each test session, composed of both tasks, lasted about 90 minutes.

\section{Results for Task 1}

In this task, subjects travelled through an extended route using either HD or tungsten-halogen low-beam headlamps, with no specific instructions to pay attention to colour appearance of stop signs or other objects. Analyses of variance evaluated the differences in responses to the 16 questions in Table 1. The analyses used the following as main factors:

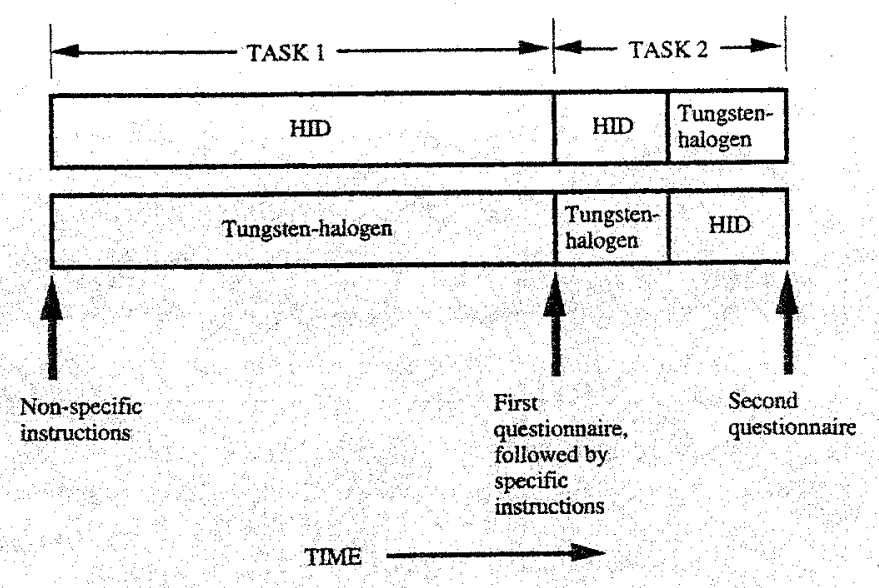

Figure 3 A schematic diagram of the design of both tasks in this study. Half of the subjects tad the sequence of headlamps shown in the upper bar, and the other half had the sequence shown in the lower bar.

headlamp, age group, and sex. (Preliminary analyses found that seating position had no effect on responses to any of the 16 questions. Consequently, the data were collapsed across the three seating positions.)

\subsection{Effects of headlamp}

The main finding is that for none of the 16 questions were the differences between the two types of headlamps statistically significant. The mean responses are shown in Table 4. Three of the questions asked subjects whether they noticed anything particular about traffic signs (Question 9), stop signs (Question 10), or brake and tail lights (Question 15). The comments to these open-ended questions are summarised in Table 5. The comments are grouped into four categories: positive (e.g. brighter, showed up well, easy to read), negative (e.g. word STOP not as obowns, colour bleached out), irrelevant (e.g. they [traffic signs] had a $V$-shaped pattern), and none. There is

Table 4 Mean responses by each headlamp type to the questions in Task 1. Questions 1-8, 11-14 and 16 used the following five-point response scale: 1 - very poor, $2=$ poor, $3=$ fair, 4 $=$ good, 5 - very good. Questions 9,10 and 15 used a yes/no response scale, which in this table is coded as $1=$ yes and $2=$ no, $(\mathrm{T}-\mathrm{H}=$ angsten-halogen, $\mathrm{HD}=$ high-imtensity discharge)

\begin{tabular}{|c|c|c|c|}
\hline \multirow{2}{*}{$\begin{array}{l}\text { Number } \\
\text { (from Table } 1 \text { ) }\end{array}$} & \multirow[t]{2}{*}{ Question } & \multicolumn{2}{|c|}{ Mean response } \\
\hline & & $\mathrm{TH}$ & Ho \\
\hline 1 & Overall performance & 43 & 42 \\
\hline 2 & Performance on expressways & 42 & 42 \\
\hline 3 & Performance on residential streets. & 42 & 40 \\
\hline 4 & Performance on straight roads & 43 & 39 \\
\hline 5 & Performance on curves & 37 & 38 \\
\hline 6 & Helping to derect objects in the distance & 3.6 & 3.8 \\
\hline 7 & Making objects stand out from their background & 3.8 & 40 \\
\hline 8 & Helping to see the colour of objects & 3.8 & 3.8 \\
\hline 9 & Anything particular about traffic signs? & 1.6 & 14 \\
\hline 10 & Anything particular about stop signs? & 16 & 1.4 \\
\hline 11 & Visibility of stop signs at far distance & 38 & 4.1 \\
\hline 12 & How well stop signs stood out from background & 40 & 43 \\
\hline 13 & Legibility of stop signs & 4.1 & 42 \\
\hline 14 & Quality of the red colour of stop signs & 3.8 & 3.8 \\
\hline 15 & Anything particular about brake and tail lights? & 19 & 20 \\
\hline 16 & Quality of the red colour of brake and tail lights & 3.9 & 3.9 \\
\hline
\end{tabular}


Table 5 Summary of comments to the three open-ended questions in Task 1 . The entries are percentages, for each headlamp type, of subjects who fell into each comment-type category. Because of rounding, the percentages do not necessarily add up to 100 . ( $\mathrm{T}-\mathrm{H}=$ tungsten-halogen, $\mathrm{HD}=$ high-intensity discharge)

\begin{tabular}{|c|c|c|c|c|c|c|c|c|c|}
\hline \multirow[t]{2}{*}{$\begin{array}{l}\text { Number } \\
\text { (from Table 1) }\end{array}$} & \multirow[t]{2}{*}{ Question } & \multicolumn{2}{|c|}{$\begin{array}{l}\text { Positive } \\
\text { comments }\end{array}$} & \multicolumn{2}{|c|}{$\begin{array}{l}\text { Negative } \\
\text { comments }\end{array}$} & \multicolumn{2}{|c|}{$\begin{array}{l}\text { Irrelevant } \\
\text { comments }\end{array}$} & \multicolumn{2}{|c|}{ No comments } \\
\hline & & $\mathrm{T}-\mathrm{H}$ & HID & $\mathrm{T}-\mathrm{H}$ & $\mathrm{HD}$ & $\mathrm{T}-\mathrm{H}$ & $\mathrm{HID}$ & $\mathrm{T}-\mathrm{HI}$ & HED \\
\hline 9 & $\begin{array}{l}\text { Did you notice anything } \\
\text { particular about traffic signs? }\end{array}$ & 28 & 44 & 11 & 6 & 6 & 6 & 56 & 44 \\
\hline 10 & $\begin{array}{l}\text { Did you notice anything } \\
\text { particular about stop signs? }\end{array}$ & 28 & 56 & 6 & 6 & 11 & 0 & 56 & 39 \\
\hline 15 & $\begin{array}{l}\text { Did you notice anything par- } \\
\text { ticular about the brake and tail } \\
\text { lights on vehicles ahead of you? }\end{array}$ & 6 & 0 & 0 & 0 & 0 & 0 & 94 & 100 \\
\hline
\end{tabular}

no evidence in Table 5 to suggest that the HID headlamps lead to more negative comments.

\subsection{Effects of age group and sex}

Age group had a statistically significant main effect only on responses to Question 3 (performance on residential streets), $F(2,24)=4.54, p=0.021$, with middle aged subjects assigning more favorable ratings ( 4.6 on a five-point scale) than older subjects (4.1) and younger subjects (3.5). Sex had a statistically significant main effect only on Question 9 (anything particular about traffic signs), $F(1,24)=9.00, p=0.006$, with males responding 'yes' more often than females $(67 \%$ versus $33 \%)$.

\section{Results for Task 2}

In this task, subjects travelled through a short route using both types of headlamp consecutively, with specific instructions to pay attention to the colour appearance of stop signs and other objects. The results for each of the five questions in this task are presented in turn. The main factors in these analyses of variance were actual headlamps (i.e. headlamps to be evaluated), prior headlamps (i.e. headlamps used in Task 1), age group, and sex. (Preliminary analyses found that seating position had no effect on responses to any of the five questions. Consequently, the data were collapsed across the three seating positions.) The effects of age group and sex, as well as the effects of interactions involving these factors, were not statistically significant for any of the five questions. Thus, what follows is the presentation of the effects of actual and prior headlamps.

\subsection{Overall performance of each headlamp type (Question 1)}

The effect of actual headlamps was statistically significant, $F(1,24)=14.67, p=0.0008$, with the HID headlamps rated as better than the tungsten-halogen headlamps ( 4.2 versus 3.6 on a five-point scale). The effect of prior headlamps was not significant; $F(1,24)=2.04, p=0.166$. However, the interaction between the actual and prior headlamps was significant; $F(1,24)=23.76, p=0.0001$, with the HIDs rated as better than the tungsten-halogens only by subjects who had the HIDs as the prior headlamps in Task 1 (see Figure 4).

7.2 Performance of each headlamp type in making objects in general stand out from their backgrounds (Question 2)

The effect of actual headlamps was statistically significant; $F(1,24)=16.29, p=0.0005$. with the HID headlamps rated as better than the tungsten-halogen headlamps (4.3 versus 3.5 ). The effect of prior headlamps was not significant; $F(1,24)<$

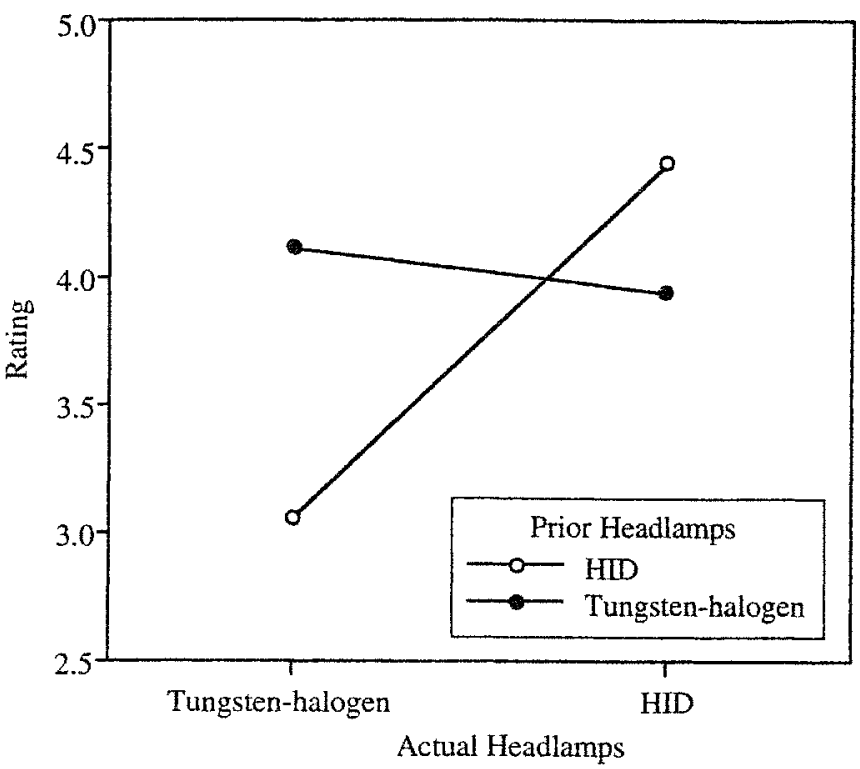

Figure 4 The effect of actual and prior headlamps on overall performance. The ratings used the following five-point scale: $1=$ very poor, $2=$ poor, $3=$ fair, $4=$ good, $5=$ very good.

1. The interaction between the actual and prior headlamps was significant; $F(1,24)=7.48, p=0.012$, with the HIDs rated as better than the tungsten-halogens primarily by subjects who had the HIDs as the prior headlamps in Task 1 (see Figure 5).

7.3 Performance of each headlamp type in helping to see the colours of objects in general (Question 3)

The effect of actual headlamps was not statistically significant; $F(1,24)=2.68, p=0.114$, nor was the effect of prior headlamps; $F(1,24)<1$. The interaction between the actual and prior headlamps was significant; $F(1,24)=7.00, p=$ 0.014 , with the HIDS rated as better than the tungsten-halogens only by subjects who had the HIDs as the prior headlamps in Task 1 (see Figure 6).

\subsection{Performance of each headlamp type in making stop signs stand out from their backgrounds (Question 4)}

The effect of actual headlamps was statistically significant; $F(1,24)=10.87, p=0.003$, with the HID headlamps rated as better than the tungsten-halogen headlamps ( 4.4 versus 3.7 ). The effect of prior headlamps was not significant; $F(1,24)<$ 1. The interaction between the actual and prior headlamps was significant; $F(1,24)=6.11, p=0.021$, with the HIDs rated as better than the tungsten-halogens primarily by subjects 


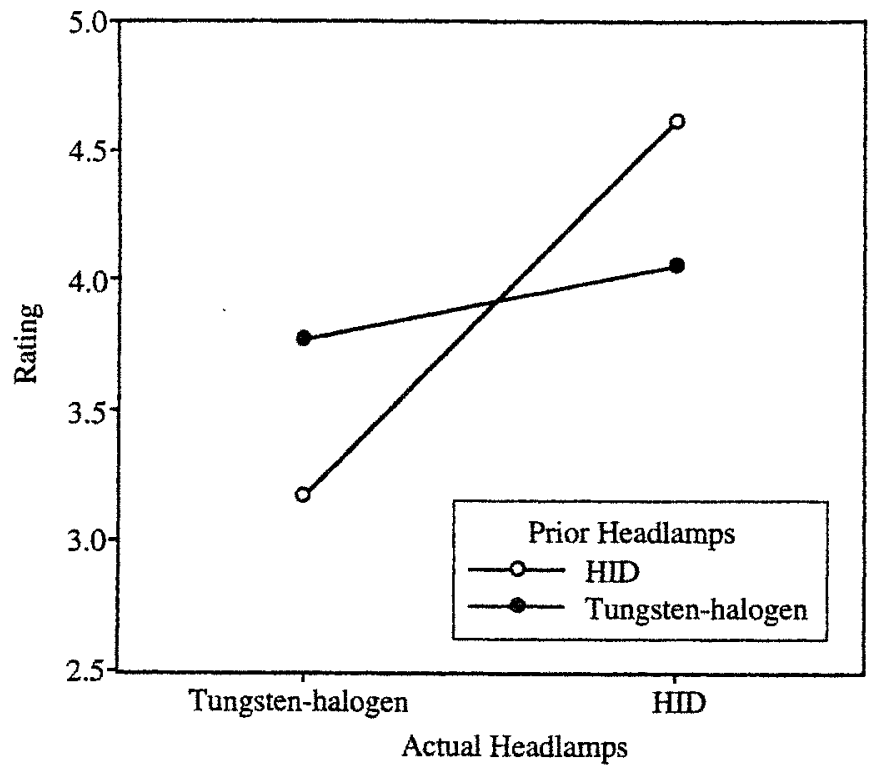

Figure 5 The effect of actual and prior headlamps on making objects in general stand out from their backgrounds. The ratings used the following five-point scale: $1=$ very poor, $2=$ poor, $3=$ fair, $4=$ good, $5=$ very good.

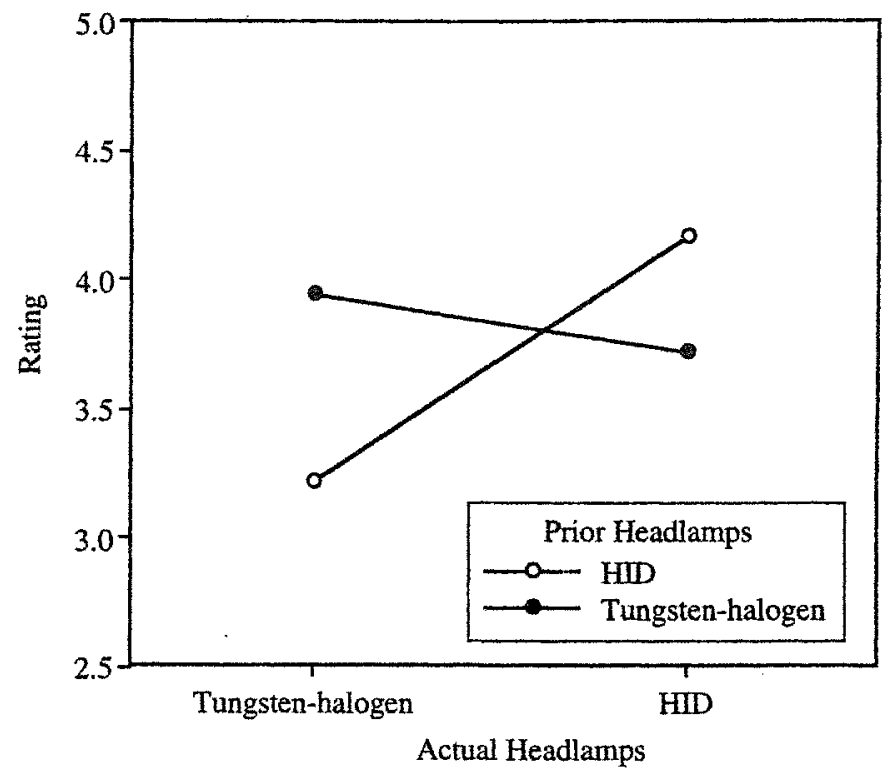

Figure 6 The effect of actual and prior headlamps on helping to see the colours of objects in general. The ratings used the following five-point scale: $1=$ very poor, $2=$ poor, $3=$ fair, $4=$ good, $5=$ very good.

who had the HIDs as the prior headlamps in Task 1 (see Figure 7).

\subsection{Performance of each headlamp type in helping to see the colours of stop signs (Question 5)}

The effect of actual headlamps was not statistically significant; $F(1,24)=1.03, p=0.320$, nor was the effect of prior headlamps; $F(1,24)<1$. The interaction between the actual and prior headlamps was significant; $F(1,24)=7.81, p=$ 0.010 , with the HIDs rated as better than the tungsten-halogens only by subjects who had the HIDs as the prior headlamps in Task 1 (see Figure 8).

Table 6 summarises the effects of actual headlamps and prior headlamps, as well as their interactions on the ratings.

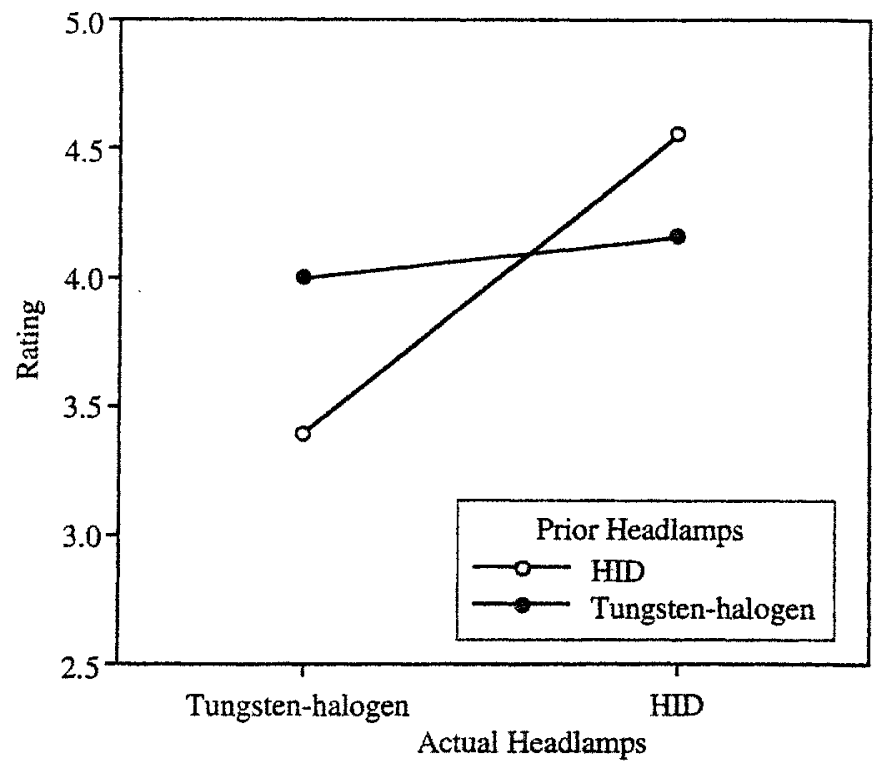

Figure 7 The effect of actual and prior headlamps on making stop signs stand out from their backgrounds. The ratings used the following five-point scale: $1=$ very poor, $2=$ poor, $3=$ fair, $4=$ good, $5=$ very good.

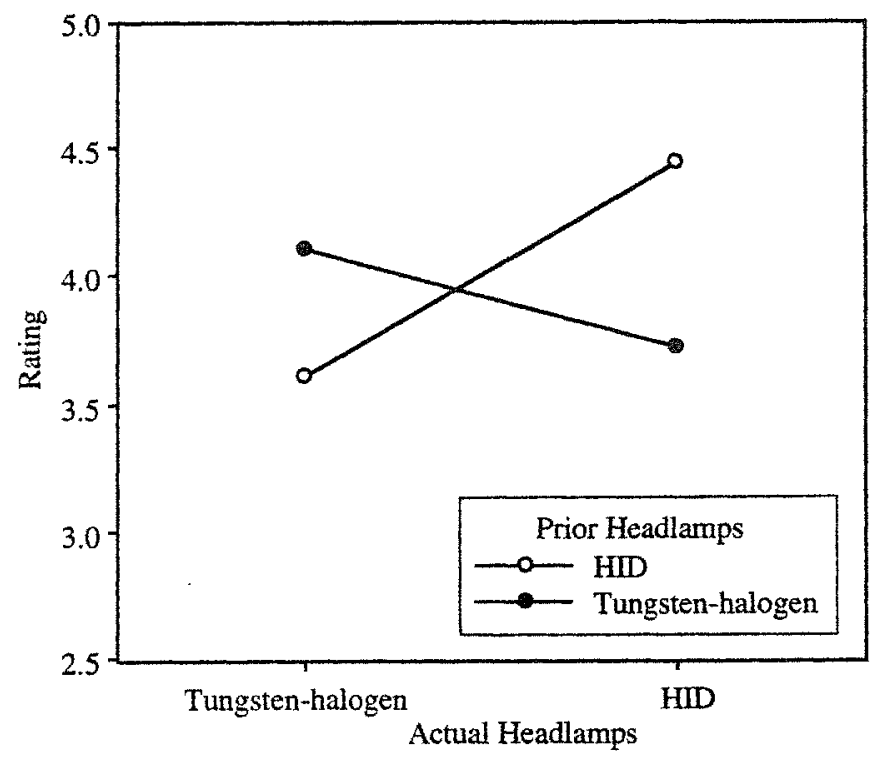

Figure 8 The effect of actual and prior headlamps on helping to see the colours of stop signs. The ratings used the following five-point scale: $1=$ very poor, $2=$ poor, $3=$ fair, $4=$ good, $5=$ very good.

\section{Conclusions}

This study evaluated subjects' impressions of performance of HID headlamps after in-traffic experience, with a special emphasis on colour appearance of stop signs. The same subjects participated in two tasks. In Task 1 the subjects drove (or rode) $19 \mathrm{~km}$ through a variety of roadway environments using either HID or tungsten-halogen low-beam headlamps. The instructions to subjects for this task did not mention colour appearance. Task 2 involved a direct comparison of HID and tungsten-halogen headlamps. In this task the subjects drove (or rode) twice along a $4 \mathrm{~km}$ route in a residential area, and they were instructed to pay attention to the colour appearance of stop signs and other objects.

The main finding from Task 1 is that the subjects who experienced HID headlamps did not report more (or fewer) spontaneous negative comments on colour appearance of stop signs 
Table 6 Summary of the statistical significance (at the 0.05 level) of the effects in Task 2

\begin{tabular}{|c|c|c|c|c|}
\hline $\begin{array}{l}\text { Number } \\
\text { (from Table 2) }\end{array}$ & Question & $\begin{array}{l}\text { Actual headlamps } \\
\text { (headlamps in } \\
\text { Task } 2 \text { ) }\end{array}$ & $\begin{array}{l}\text { Prior headlamps } \\
\text { (headlamps in } \\
\text { Task 1) }\end{array}$ & $\begin{array}{l}\text { Actual headlamps } \\
\times \text { prior headlamps }\end{array}$ \\
\hline 1 & $\begin{array}{l}\text { Rate the overall performance } \\
\text { of each lamp type. }\end{array}$ & Significant & Not significant & Significant \\
\hline 2 & $\begin{array}{l}\text { Rate the performance of each lamp type } \\
\text { in making objects in general stand out } \\
\text { from their background. }\end{array}$ & Significant & Not significant & Significant \\
\hline 3 & $\begin{array}{l}\text { Rate the performance of each lamp type } \\
\text { in helping to see the colours of objects } \\
\text { in general. }\end{array}$ & Not significant & Not significant & Significant \\
\hline 4 & $\begin{array}{l}\text { Rate the performance of each lamp type } \\
\text { in making stop signs stand out } \\
\text { from their background. }\end{array}$ & Significant & Not significant & Significant \\
\hline 5 & $\begin{array}{l}\text { Rate the performance of each lamp type } \\
\text { in helping to see the colours of stop signs. }\end{array}$ & Not significant & Not significant & Significant \\
\hline
\end{tabular}

or other objects than did the subjects who experienced tungsten-halogen headlamps. Furthermore, the evaluations of the overall performances of the two types of headlamps were not different.

In the direct comparison of Task 2 there was no evidence of problems with colour appearance when using HID headlamps. Moreover, subjects preferred HID headlamps in terms of overall performance, in making objects in general stand out from their background, and in making stop signs stand out from their background. However, for all three of these aspects there were statistically significant interactions between the actual headlamps evaluated and the prior headlamps to which the subjects were exposed in Task 1. Specifically, the preference for HID headlamps was present primarily for subjects who had HID headlamps in Task 1 . This finding suggests that a somewhat extended exposure (about 30 minutes $/ 19 \mathrm{~km}$ ) to HID headlamps is necessary for the HID preference to develop, since the 7 minute $/ 4 \mathrm{~km}$ exposure in Task 2 did not appear to be sufficient for those subjects who had tungsten-halogen headlamps in Task 1.

The information in Figure 2 indicates that at the United States test points the luminous intensity outputs of the HID headlamps were not substantially different from those of the tungsten-halogen headlamps. However, the HID headlamps had higher peak outputs and provided more laterally spread illumination. Consequently, the obtained differences in ratings between the two types of headlamps could be a consequence of the differences in luminous intensity. An alternative explanation is the difference in the spectral power distributions (see Figure 1). It is possible that the spectral power distribution of the HID headlamps led to increased brightness contrast and/or colour contrast for certain object/background combinations. This speculative explanation could account for the reported advantage of the HIDs in making objects stand out from their backgrounds, and this, in turn, could have resulted in the overall preference for the HIDs. However, the present study does not allow us to identify whether the obtained subjective preferences for HID over tungsten-halogen headlamps are the consequence of differences in light output or spectral power distribution.

Previous studies found that HID headlamps result in substantial colorimetric shifts ${ }^{(1,2)}$ and that laboratory observers are sensitive to such shifts $(3,6,7)$. The lack of negative findings in the present study concerning HID headlamps suggests that the resultant colorimetric shifts might not be of sufficient magnitude to cause a problem in actual driving. However, the pre- sent study did not use a performance measure, such as a frequency of missed stop signs; it was based on the assumption that if a colorimetric shift is large enough to affect performance, it will also affect subjective ratings. While this seems reasonable, it remains an assumption.

In summary, the results of this study provide no evidence of problems with colour appearance of stop signs and other objects when using HID headlamps. Furthermore, the study indicates that observers perceive HID headlamps as helping stop signs and other objects to stand out from their backgrounds. Finally, the present results imply that, given a somewhat extended exposure to HID headlamps, drivers would prefer them over current tungsten-halogen headlamps.

\section{Acknowledgments}

Appreciation is extended to the members of The University of Michigan Industry Affiliation Program for Human Factors in Transportation Safety for support of this research. The current members of the Affiliation Program are Adac Plastics, Bosch, Carello Lighting, Chrysler, Donnelly, Ford, GM (Inland Fisher Guide Division), Ichikoh Industries, Koito Manufacturing, LESCOA, Libbey-Owens-Ford, Muth Advanced Technologies, Osram Sylvania, Philips Lighting, PPG Industries, Stanley Electric, United Technologies Automotive Systems, Valeo, Wagner Lighting, and 3M.

\section{References}

1 Sivak $M$, Simmons $C J$ and Flannagan $M$ Colours of retroreflective traffic sign materials when illuminated by high-intensity discharge headlights Int. F. Vehicle Design 12(3) 284-295 (1991)

2 Flannagan $\mathrm{M}$, Sivak $\mathrm{M}$, Gellatly $\mathrm{A}$ W and Luoma J Ranges of stop sign chromaticity under tungsten-halogen and high-intensity discharge illumination Report No. UMTRI-92-17 (Ann Arbor: The University of Michigan Transportation Research Institute) (1992)

3 Sivak $M$, Flannagan $M$, Gellatly A W and Luoma J Subjective preferences for red colour of stop signs: Implications for the design of highintensity discharge headlamps Color Res. Applic. 17(5) 356-360 (1993)

4 Kantowitz B H and Sorkin R D Human factors (New York: Wiley) (1983) 
5 Lamps, reflective devices and associated equipment Standard 108 in Code of federal regulations (Washington, DC: Office of the Federal Register) (1991)

6 Collins B L Evaluation of colours for use on traffic control devices Report 88-3894 (Gaithersburg, MD: National Institute of Standards and Technology) (1988)

7 Arens J B, Saremi A R and Simmons C J Colour recognition of retroreflective traffic signs under various lighting conditions Public Roads 55 (1) $1-7(1991)$

\section{Discussion}

\section{R H Simons (Consultant)}

These were very well designed experiments in that subjects were separated according to their age and sex. This means that there were only six participants in each group which makes the detection of small differences in preferences or behaviour difficult. However, no doubt the sensitivity of the evaluations was sufficient for the purpose.

I have two queries. First, I cannot see any mention of street lighting. Was this present? If it was I would expect that it would have some effect on the conspicuity of objects. Second, Figure 2 indicates that the two types of headlight have very similar light distributions, yet the text says that the HID lamps had a maximum light output of about $30000 \mathrm{~cd}$ whereas that of the tungsten-halogen lamps was about $22000 \mathrm{~cd}$. These two statements do not seem compatible. Moreover, Figure 2 indicates the presence of intensities of about $120000 \mathrm{~cd}$, which are far greater than the maximum light outputs mentioned above. Could the authors please explain this discrepancy? Also, it would be interesting to know the luminous flux emitted by each type of lamp and the electrical power consumed. Is it possible that the greater spread and possible greater light output of the HID lamps compensated for any deficiency in their colour rendering?

\section{Authors' reply to discussion}

We appreciate the discussant's kind words with regard to the design of the study. However, we disagree with the comment that the number of subjects in the smallest subdivision of the design (six) determines the sensitivity of the experiment with regard to most questions of interest. It is a basic aspect of factorial designs that the effects that are usually of primary interest (in this case, for example, the main effect of the type of light source) are estimated by pooling data across the smaller subdivisions of the design. In general, the total number of subjects ( 36 in this case) is more relevant than the number in the smallest subdivision.
Because the study was performed on public roads, street lighting was present on most sections of the routes. However, we believe that the presence of street lighting did not unduly influence the comparisons between the two types of headlamps. There are three reasons for this. First, the two types of lamps were compared on the same routes in both Task 1 and Task 2, and so any direct influence of street lighting was the same for the two lamp types. Second, the road lighting encountered on the route was varied enough to suggest that it was approximately representative of typical US lighting. Thus, any effects of street lighting in this study should also be characteristic of normal driving. Third, the retroreflective efficiency of retroreflective traffic signs (the objects of primary interest in this study) decreases rapidly as the observation angle is increased. The observation angle is the angle formed by the light source, sign, and the eyes of the observer. That angle is almost always much smaller for the headlamps than for other light sources in the driving environment. Consequently, the light that reaches the driver from retroreflective traffic signs is overwhelmingly that originating from the headlamps.

Figure 2 shows the light output at selected test points - the test points in the current US regulations. The maximum light outputs for the eight tested lamps turned out to be from $1.3^{\circ}$ to $1.6^{\circ}$ down, and from $2^{\circ}$ to $3.9^{\circ}$ right. The nearest controlled test point to the locations of the maxima is at $1.5^{\circ}$ down, $2^{\circ}$ right (test point 10, Figure 2). Because this test point does not coincide with the locations of all eight maxima, the photometric values at this test point only partially reflect the greater maximum output of the HID lamps.

The discussant is mistaken in stating that 'Figure 2 indicates the presence of intensities of about 120000 cd.' The maximum value shown in Figure 2 corresponds to $32449 \mathrm{~cd}$ at test point 10 for one of the Hmb headlamps. The mistake was probably due to misinterpreting the labels on the vertical axis of Figure 2, which are spaced logarithmically. The scale numbers on the vertical axis only go up to $100000 \mathrm{~cd}$, and the value of the maximum of $32449 \mathrm{~cd}$ is plotted at its correct location between $30000 \mathrm{~cd}$ and $40000 \mathrm{~cd}$.

The power consumed for the four tungsten-halogen lamps ranged from 56 to $57 \mathrm{~W}$, while for the four HID lamps it was $38 \mathrm{~W}$. We do not have information about the luminous flux emitted.

The discussant is correct in pointing out that in the present study we cannot completely separate the influence of light output and spectral power distribution. We have already acknowledged this in our Conclusions (paragraph 4 of section 8). 